grupos eram homogêneos e comparáveis. A avaliação macroscópica das placentas, não evidenciou diferença estatística entre os grupos. Em relação a análise microscópica, verificou-se a tendência de uma maior taxa de alterações isquêmicas no grupo DA, porém sem diferença estatística significativa entre os grupos. O padrão apoptótico do grupo DN, foi de $0,17 \pm 0,10 \%$ e no grupo DA, $0,18 \pm 0,11 \%$ sem diferença estatística entre os grupos, não havendo influência relacionada à cor da paciente ou à via de parto. A expressão de Bcl-2 nas placentas do grupo DN e DA apresentou-se positivos em todos os casos. Constatou-se no grupo DN taxa de apoptose compativel com resultados de placentas nor- mais a termo descritos na literatura. O grupo DA com exame dopplervelocimétrico das artérias uterinas alterado não apresentou diferença estatística significativa nas taxas de apoptose em relação ao grupo DN. O padrão apoptótico aumentado na DHEG e no RCIU, provavelmente está associado ao padrão de hipóxia gerada pelo processo patológico instalado e não está associado ao padrão hipóxia envolvido na gênese das patologias acima mencionadas.

Palavras-chave: Apoptose. Pré-eclâmpsia. Restrição do crescimento intra-útero. Placenta.

\title{
Expressão do P63 em Tumores Epiteliais do Ovário: uma Nova Evidência da Origem Alternativa dos Tumores Mucinosos
}

Autor: Omero Benedicto Poli Neto

Orientador: Prof. Dr. Francisco José Candido dos Reis

Tese de Doutorado apresentada ao Departamento de Ginecologia e Obstetrícia da Faculdade de Medicina de Ribeirão Preto da Universidade de São Paulo, em 31 de outubro de 2003

\section{Resumo}

Objetivos: avaliar a expressão do P63 em tumores ovarianos epiteliais e verificar sua associação com os tipos histológicos.

Métodos: estudamos a expressão do P63 usando um anticorpo monoclonal (clone A4A) que reconhece todas as isoformas da proteína p63. Foram incluídos 91 espécimes de cistadenomas ovarianos: 29 cistadenomas mucinosos e 62 cistadenomas serosos; e 29 espécimes de carcinomas ovarianos: 3 tumores borderline mucinosos, 3 tumores borderline serosos, 1 carcinoma seroso, 17 carcinomas serosos e 5 carcinomas de outros subtipos histológicos.

Resultados: 85,7\% dos cistadenomas e 50\% dos tumores borderline apresentaram expressão do P63. Entretanto, uma minoria $(8,7 \%)$ de carcinomas p63-positivos foi identificada $(\mathrm{p}<0,0001)$. Todos os 3 tumores borderline p63-positivos eram tumores mucinosos. $\mathrm{O}$ espécime de carcinoma mucinoso foi p63-positivo e o outro carcinoma p63-positivo foi um carcinoma seroso pouco diferenciado estadio IV. Oito cistadenomas mucinosos $(27,6 \%)$ e somente 5 cistadenomas serosos $(8,1 \%)$ foram p63-negativos $(\mathrm{p}=0,02)$.

Conclusão: estes resultados mostram que cistadenomas ovarianos são mais freqüentemente p63positivos que tumores borderline e carcinomas ovarianos. Todavia, mais cisadenomas mucinosos p63-negativos foram identificados que cistadenomas serosos. Além do mais, tumores mucinosos borderline e invasores foram p63-positivos em contraste aos serosos borderline e invasores, sugerindo que a expressão do P63 pode sofrer influência tanto da natureza quanto do tipo histológico da lesão.

Palavras-chave: P63. Ovário: câncer. Ovário: cistos oncogenes. 